\title{
BANALIDADE DO MAL, PRODUÇÃO E VEICULAÇÃO DE DISCURSOS DE ÓDIO: E A UNIVERSIDADE COM ISSO?
}

\author{
BANALITY OF EVIL, PRODUCTION AND DISSEMINATION OF HATE SPEECH: AND THE \\ UNIVERSITY WITH IT?
}

\section{LA BANALIDAD DEL MAL, LA PRODUCCIÓN Y LA DIFUSIÓN DEL DISCURSO DEL ODIO: ¿Y LA UNIVERSIDAD CON ÉL?}

Ricardo Rezer ${ }^{1}$

\begin{abstract}
RESUMO
O objetivo deste ensaio é refletir sobre as responsabilidades da universidade como instituição republicana, frente a crescente normalização da barbárie discursiva, que se manifesta, por vezes, de forma explícita, por vezes de forma dissimulada, impactando decisivamente na vida contemporânea. Parto do pressuposto de que vivemos em um tempo avesso ao pensamento, no qual, discursos vão sendo formulados sem considerar suas consequências na ampla esfera social, bem como, sem tomar como referência o bem comum. $O$ texto se subdivide em dois momentos. No primeiro, apresento uma breve reflexão sobre a banalidade do mal, partindo das contribuições de Hannah Arendt (1906-1975). № segundo, apresento argumentos na direção de tensionar as responsabilidades da universidade frente a este cenário, entendendo-a como instituição republicana que ainda pode contribuir para a construção de uma sociedade comprometida com o bem comum. Finalizo afirmando que a universidade não pode compactuar com narrativas que naturalizam o ódio, normalizam a agressividade, bem como, desacreditam e fazem desacreditar que a paz e o bem podem ser o motor das sociedades que existem em âmbito planetário.
\end{abstract}

PALAVRAS-CHAVE: Liberdade de expressão. Discursos de ódio. Educação Superior.

\section{ABSTRACT}

The objective of this essay is to reflect on the responsibilities of the university as a republican institution, in the face of the growing normalization of discursive barbarism, which manifests itself, sometimes, explicitly, sometimes covertly, decisively impacting contemporary life. I start from the assumption that we live in a time that is not good to thought, in which discourses are being formulated without considering their consequences in the broad social sphere, as well, without reference to the common good. The text is subdivided into two moments. In the first, I present a brief reflection on the banality of evil, based on the contributions of Hannah Arendt (1906-1975). In the second, I present arguments in the direction of tensionar the responsibilities of the university against this scenario, understanding it as a republican institution that can still contribute to the construction of a society more committed to the common good. I conclude by stating that the university cannot condone narratives that naturalize hatred, normalize the aggressiveness, as well as discredit and make discredit that peace and good can be the engine of societies that exist on a planetary level.

KEY-WORDS: Freedom of expression.. Hate Sppech. Higher education.

\section{RESUMEN}

El objetivo de este ensayo es reflexionar acerca de las responsabilidades de la universidad como institución republicana, frente a la creciente normalización de la barbarie discursiva, que se manifiesta, a veces, de forma explícita, a veces de forma encubierta, impactando decisivamente en la vida contemporánea. Parto del presupuesto de que vivimos en un tiempo reverso al pensamiento, en el cual,

\footnotetext{
1 Realizou estudos de Pós-Doutorado no Centro de Estudos Sociais da Universidade de Coimbra (2018). Doutorado em Educação Física (2010) na Universidade Federal de Santa Catarina, com estágio na Universidade do Porto (Porto, Portugal). Atualmente é Professor Adjunto A da Escola Superior de Educação Física da Universidade Federal de Pelotas (ESEF/UFPel). E-mail: rrezer@hotmail.com
} 
discursos van siendo formulados sin considerar sus consecuencias en la amplia esfera social, así como, sin tomar como referencia el bien común.El texto se subdivide en dos partes. En la primera, presento una breve reflexión sobre la banalidad del mal, partiendo de las contribuciones de Hannah Arendt (19061975). En la segunda, presento argumentos en la dirección de tensionar las responsabilidades de la universidad frente a este escenario, entendiéndola como institución republicana que aún puede contribuir con la construcción de una sociedad comprometida con el bien común. Concluyo afirmando que la universidad no puede tolerar narrativas que naturalizan el odio, normalizan la agresividad y desacreditan y hacen desacreditar que la paz y el bien pueden ser el motor de las sociedades que existen a nivel planetario.

PALABRAS-CLAVE: Libertad de expresión. Discurso de ódio. Educación universitária.

\section{CONSIDERAÇÕES INICIAIS}

O ensaio que passo a apresentar é fruto de uma série de reflexões, diálogos e análises que procuram pensar melhor sobre o tempo no qual vivemos, em meio a uma pandemia (causada pelo vírus Sars-Cov2²) que, por um lado, vai tornando a vida mais sôfrega, mais individualizada e mais incerta, por outro, escancara a necessidade de pensá-la como uma produção coletiva, mais solidária, um "fazendo junto" (sem idealizações ingênuas) que nos coloca na obrigação de aprender a nobre arte da convivência, princípio fundante para a vida em sociedade.

Discussões sobre "discursos de ódio" vem se avolumando nos últimos anos, sendo abordado em diversos livros, artigos, jornais, canais de youtube, entre outros, como por exemplo, o trabalho de Cavalcante Filho (2017) ${ }^{3}$. Via de regra, associado a "liberdade de expressão", o tema representa uma janela de oportunidades para ponderar com maior cuidado sobre aspectos complexos e polêmicos da conjuntura contemporânea, tanto na realidade brasileira, como na realidade internacional.

Momentos de crise permitem evidenciar o melhor e o pior do humano, o que exige pensamento e reflexão, no sentido de ponderar sobre as melhores decisões a tomar nos mais diversos âmbitos sociais. Se por um lado, vemos emergir forte solidariedade entre pessoas, desde os cuidados dos profissionais de saúde até o auxílio voluntário aos necessitados, por outro, a barbárie parece imperar com intensidade, tanto nas estatísticas do número crescente de mortos no cenário nacional e internacional, no descaso (com ares de deboche) de lideranças

\footnotetext{
2 Nome oficial do vírus que atinge o mundo em 2020 e invade 2021, levando a um estado de emergência de saúde pública de importância internacional. 0 nome foi escolhido pela Organização Mundial da Saúde (OMS) para facilitar a identificação em estudos científicos e também a divulgação na imprensa, além de evitar confusões com outros vírus da mesma família.

${ }^{3}$ Nesta obra, o autor analisa o "discurso do ódio" como um fenômeno, muitas vezes, tratado como uma forma de exercício da liberdade de expressão, tomando-a como prerrogativa para o insulto de pessoas ou grupos de pessoas, propagando o ódio por diversos 'motivos' (raça, religião, cor, origem, gênero, orientação sexual etc.).
}

Revista de Ciências Humanas, Frederico Westphalen - RS, , v. 22, n.1, p. 101-123, jan./abr. 2021.

Recebido em: 23/02/2021 $\quad$ Aceito em: 02/06/2021


políticas frente ao cenário mórbido que vivemos, como também na enxurrada de impropérios e Fake News veiculados em muitas redes sociais (em alguns casos, fomentados por figuras políticas de maior ou menor expressão midiática, que parecem não ter ideia - ou não se importar - com os impactos de sua irresponsabilidade).

Tomando como referência estas breves considerações introdutórias, o objetivo deste ensaio, fruto de um estudo teórico, é refletir acerca das responsabilidades da universidade, como instituição republicana, frente à crescente normalização da barbárie discursiva, que se manifesta, por vezes, de forma explícita, por vezes de forma dissimulada (uma forma de manifestação também muito perigosa), impactando decisivamente na vida contemporânea.

Parto do pressuposto de que vivemos em um tempo avesso ao pensamento, no qual discursos intempestivos e irresponsáveis vão sendo formulados sem considerar suas consequências na ampla esfera pública, bem como, sem tomar como referência o bem comum, impulsionado por sectarismos e um egoísmo opinativo que banaliza a agressividade, a dissimulação e a negação do outro. Nessa direção, não podemos esquecer que discursos produzem mundo e legitimam formas de viver e conviver, projetando, na concretude da vida, narrativas que mudam ou intensificam determinados modos de ser, agir e pensar.

$\mathrm{Na}$ direção de sustentar este pressuposto, bem como, enfrentar os desafios derivados do objetivo geral, subdividi o ensaio em dois momentos. No primeiro, apresento uma reflexão sobre a banalidade do mal, partindo das contribuições de Hannah Arendt (1906-1975). No segundo, apresento argumentos na direção de fundamentar melhor as responsabilidades da universidade frente a este cenário, entendendo-a como instituição republicana que ainda pode contribuir para a produção da vida digna em sociedade, potencializando nossa capacidade de "com viver". Talvez, com a pandemia, possamos compreender que a vida em sociedade exige responsabilidade, respeito e alteridade, pois, definitivamente, necessitamos do outro na produção da vida coletiva - não há como "sair do mundo", condição que nos coloca sob 0 mesmo "teto", no mesmo oikos (casa), e não tem jeito.

\section{MOMENTO - UMA LEITURA PANORÂMICA: A BANALIDADE DO MAL COMO CARACTERIZAÇÃO PARA O DENOMINADO "DISCURSO DE ÓDIO"}

O que proponho, portanto, é muito simples: trata-se apenas de refletir sobre o que estamos fazendo. (ARENDT, 2008, p. 13).

Em um de seus livros mais importantes, "A condição Humana" (publicado originalmente em 1958), Hannah Arendt afirma, como expresso na epígrafe deste tópico, que seu projeto 
intelectual se funda na perspectiva de "[...] pensar o que estamos fazendo" (ARENDT, 2008). Nesse caso, em meio a uma aparente simplicidade, talvez uma das tarefas mais revolucionárias de nosso tempo seja mesmo, pensar com radicalidade sobre o que estamos fazendo e para onde estamos indo (neste caso, a grande revolução da universidade seria potencializar esta possibilidade, algo na contramão do que se percebe na contemporaneidade, como tratarei mais a frente). Afinal, por que fazemos o que fazemos? Por que pensamos como pensamos? Ou, como Hannah Arendt se refere, o que estamos fazendo? São perguntas por demais necessárias de serem enfrentadas em nosso tempo, por meio da atividade do pensamento, do estudo e do diálogo.

A expressão "banalidade do mal" foi produzida por Hannah Arendt, em seu livro "Eichmann em Jerusalém - um relato sobre a banalidade do mal", publicado em 1963 (ARENDT, 2000). Neste livro, fruto de uma reportagem para a revista The New Yorker, ela narra 0 julgamento de Adolf Eichmann, realizado em 01 de junho de 1962, na cidade de Jerusalém. No texto, Arendt apresenta uma descrição do mal como fruto da ausência e/ou da incapacidade de reflexão, portanto, de pensamento. Einchmann tinha sido responsável por gerenciar de maneira eficaz e qualificada a logística das deportações de judeus para campos de extermínio das zonas ocupadas pelos alemães durante a Segunda Guerra Mundial.

Ao longo da arquitetura arendtiana, vamos percebendo que a produção do mal não se encontra presente em um determinado front específico (o que dilui a ideia de "eles" x "nós"), mas sim, se coloca como uma produção que se enraíza de forma orgânica e, por vezes, imperceptível, na vida cotidiana de pessoas comuns, consideradas, inclusive, "boas pessoas" ou para usar uma expressão recorrente nos últimos dias, "pessoas de bem". Nessa direção, o mal pode ser produzido também, por figuras banais, medíocres, por vezes, patéticas, como Eichmann, que, em sua perspectiva, entendia que apenas cumpria de forma qualificada as ordens que recebia e, que, por isso mesmo, não deveria ser condenado, mas sim, condecorado 4 - algo próximo do que se percebe na realidade brasileira, na discussão que envolve o uso de tortura no período vivido no Brasil a partir do golpe midiático-civil-militar de 1964. Neste caso, os

\footnotetext{
${ }^{4}$ Neste caso, pelas análises de Arendt, o sentimento de Eichmann parecia ser de "missão cumprida", tal como mencionado pelo ex-Ministro da Saúde, Eduardo Pazuello, em seu depoimento na Comissão Parlamentar de Inquérito (CPI) nos dias 18 e 19/05/2021. A chamada "CPI da Covid" tem o objetivo de apurar se houve falhas por parte do Governo Federal no enfrentamento à pandemia. Em seu depoimento de 18/05, o ex-Ministro afirmou que sua saída do Ministério, em meio ao crescimento significativo do número de contágios e óbitos devido ao Sars-CoV2, se deu pelo fato de que sua missão estava cumprida (?).
} 
torturadores estariam a "serviço da pátria" e seus atos, portanto, validados pelo objetivo maior a ser defendido - ver mais sobre o golpe de 1964 em Silva (2017).

Nesse caso, narrativas desta ordem potencializam "A crise na educação", problema já evidenciado por Arendt em texto datado de 1957 - uma crise contemporânea mais de 50 anos depois de sua publicação (ARENDT, 1992). No texto ela chama a atenção que tempos de crise nos fazem voltar as questões mesmas e exige respostas novas ou velhas, mas adverte para 0 desastre se pretendermos resolver a crise com base em pensamentos feitos e preconceitos. Revisionismos e negacionismos devem, portanto, ser examinados a partir de referências que nos permitam discernimento e base de sustentação para assumir a posição que entendermos como adequadas para determinada situação. Para isso, não é prudente deslegitimar apressada e irresponsavelmente, a produção cultural edificada ao longo da história da humanidade ${ }^{5}$. E isso exige uma postura aberta e crítica frente a tradição, como possibilidade de que as novas gerações aprendam sobre o legado da humanidade, bem como, aprendam com os erros e acertos do passado. Nada menos do que um grande desafio no âmbito educacional.

Bem verdade, retomando a questão de Eichmann, não desconsidero as críticas aos argumentos de Hannah Arendt, como por exemplo, o livro da filósofa e historiadora alemã Bettina Stangneth (STANGHETH, 2011), "Eichmann vor Jerusalem - das unbehelligte Leben eines Massenmörders" (Tradução livre: Eichmann antes de Jerusalém: a vida tranquila de um assassino em massa). O livro apresenta uma investigação produzida sobre milhares de páginas escritas por Eichmann, no qual Stangneth conclui que ele era um ideólogo anti-semita, inteligente e manipulador, que criou uma máscara de burocrata acéfalo para o julgamento de Jerusalém. Em sua investigação, ela conclui que Eichmann era astuto e plenamente consciente da sangrenta tarefa que the cabia (KRAUZE, 2011).

Também não desconsidero os riscos na associação desta referência ao tema deste texto, reconhecendo que Hannah Arendt não se propôs a produzir um tratado teórico sobre a natureza do mal. Como aponta Xarão (2017), cabe examinar com cuidado a banalização da expressão "banalidade do mal", por vezes, utilizada para descrever e analisar eventos e fenômenos muito distintos daqueles que lhe deram origem.

Mesmo considerando tais riscos, entendo que os argumentos de Hannah Arendt se tornam fecundos para esta abordagem, na medida em que permitem refletir acerca da necessidade de reconhecer a "ausência de pensamento" e, por consequência, a normalização

\footnotetext{
${ }^{5}$ Não basta, por exemplo, acreditar que a terra seja plana para que ela passe, na realidade, a ter este formato. 
do mal, como problemas nevrálgicos do mundo contemporâneo. Sem pensamento reflexivo, pautado pela crítica e pela ética, não pode haver reconhecimento de que nossa ação possa ter sido (ou estar sendo) inadequada ou violenta. $E$, se não há reconhecimento de infração moral, por consequência, não há auto responsabilização pelo mal, algo muito comum nestes tempos difíceis de 2021 vividos na realidade brasileira. Certamente, o mal pode ser arquitetado e projetado sistematicamente com maestria e racionalidade, de forma cientificamente planejada (e creio não haver quem duvide disso). Porém, não podemos desconsiderar que a incapacidade de pensar, bem como, de se colocar no lugar do outro (alteridade), conforme sinaliza Arendt (2000), representa considerar que a maldade do mundo pode assumir formas terrivelmente normais, na qual, aquele que produz o mal, inclusive, pode imaginar estar fazendo o bem - uma complexa condição paradoxal na produção do mal, comum ao longo da história: a realização do mal em nome de um possível "bem maior" (qualquer semelhança com elementos presentes na conjuntura contemporânea brasileira não é mera coincidência).

A questão de fundo na obra de Arendt que nos chama atenção, é a necessidade de pensarmos com maior cuidado e profundidade, as razões que levam um ser humano a produzir discursos de ódio, cometer profundas barbáries, como se isso não fosse nada demais inclusive, em nome do bem. E uma das respostas que ela produz é a de que a banalização do mal naturaliza a barbárie a tal ponto, que não possuímos mais condições de estranhá-la (ver por exemplo, os mais de 465.000 óbitos registrados na realidade brasileira, em decorrência da Covid-19 e a naturalização/banalização da morte nestes tempos, depois de mais de um ano de pandemia6).

Mesmo em meio a naturalização da barbárie, não deixa de ser assustador saber que aquele vizinho simpático que encontramos diariamente no elevador ou na saída de casa para 0 trabalho, com quem trocamos frequentemente desejos de bom dia, defende o porte de armas, a violência contra homossexuais, ou ainda, o fechamento de fronteiras para imigrantes. Algo assim não pode ser encarado como uma banalidade, pois não podemos concordar com a ideia de que andar armado, "bater" em pessoas ou práticas de xenofobia representam perspectivas de mundo que devem ser respeitadas, afinal, todos tem direito à "liberdade de expressão" ou ainda, "de opinião"7.

\footnotetext{
${ }^{6}$ Dados disponíveis pela Organização Pan-Americana da Saúde (OPAS), em https://covid19.who.int/, acesso em 03 de junho de 2021.

${ }^{7}$ Em muitos casos, o insulto passa a representar a forma corriqueira de se referir ao outro. Ver exemplo dos insultos produzidos por figuras como o ex-astrólogo e pseudo-filósofo Olavo de carvalho, o próprio Presidente da República do Brasil, Jair Messias Bolsonaro e seus filhos, Carlos, Flávio e Eduardo Bolsonaro, entre outros. 0 que está em jogo aqui é uma questão nevrálgica: o que move alguém a
} 
Não vou entrar no mérito da discussão jurídica, pois não é o foco deste texto, mas se a Constituição Federal Brasileira de 1988 (BRASIL, 1988) apresenta por expresso, o direito à livre manifestação do pensamento, bem como, o direito à livre expressão da atividade intelectual, artística, científica e de comunicação, isso não nos permite assumir a negação do outro como direito constitucional. Cabe lembrar, que constituem também objetivos fundamentais da República Federativa do Brasil promover o bem de todos, sem preconceitos de origem, raça, sexo, cor, idade e quaisquer outras formas de discriminação. E na mesma Constituição de 1988, 0 artigo Art. $5^{\circ}$, inciso XLI, afirma que "[...] a lei punirá qualquer discriminação atentatória dos direitos e liberdades fundamentais" (BRASIL, 1988). Ou seja, por princípio, há travas constitucionais que permitem considerar que não temos liberdade para praticar o mal, mesmo reconhecendo a disputa sobre os limites disso, entre diferentes leituras assumidas por diferentes segmentos sociais, inclusive, presentes em muitos discursos oficiais do atual governo brasileiro (mas também, para além dele).

Nesse aspecto, a tarefa do pensamento, bem como, a necessidade de uma ampla formação ética (aqui uma chave de leitura para pensar as responsabilidades da universidade), são imprescindíveis na direção de discernir com maior qualidade, em meio a tantos discursos de ódio que utilizam a liberdade de expressão como subterfúgio, como uma porta que, pretensamente, permite externar qualquer opinião ou desejo, mesmo que seja uma opinião ou desejo falsa e/ou que se coloque como a mais pura negação do outro8.

Considerando elementos como estes, a obra de Hannah Arendt ainda faz sentido, pois nos permite pensar que o perigo de nosso tempo, tal como ocorreu em outros episódios históricos (o nazismo, por exemplo), é que as pessoas comuns acabem não percebendo o mal, ou ainda, percebendo o mal como algo aceitável, normal, a ser normalizado - tal como se fosse mera tarefa que realizamos em nome do "dever" ou por seguir determinada orientação ideológica

insultar outra pessoa, por vezes, por motivos dos mais fúteis possíveis? Ou ainda, o que os leva a naturalizar o insulto como forma corriqueira de comunicação? Por que alguém deve ou necessita insultar alguém? $O$ insulto representa uma negação do outro que deve ser analisada desde suas motivações até suas consequências. Assim, a banalização do insulto representa uma forma de agir que não pode ser tolerada, especialmente se ela for motivada, por exemplo, por questões de raça, gênero e credo, entre outros. Como exemplo, o fato de alguém não gostar deste ensaio não confere a ninguém, o direito de me insultar, nem a mim, o direito de insultar os críticos deste ensaio.

${ }^{8}$ Por exemplo, ao ser questionado sobre a as investigações da produção e veiculação de "fake news", que tem como um dos alvos investigados, seu filho, o vereador Carlos Bolsonaro, o presidente Jair Bolsonaro afirmou que não há esquema de notícias falsas, mas sim "liberdade de expressão" e, portanto, não haveria crime. Fonte: https://www.cartacapital.com.br/politica/bolsonaro-nega-esquema-de-fakenews-isso-e-liberdade-de-expressaol, acesso em 01 de dezembro de 2020. 
(uma crítica que cabe tanto ao amplo espectro político do campo da esquerda, como do campo da direita, bem como, aqueles que se colocam mais ao centro).

A expressão irresponsável de opiniões rasas, sem a devida reflexão e lastro, não pode ser tomada como referência de mundo, muito menos, como verdade, sem a devida análise e crítica. Se não pode haver campo político ou epistemológico blindado a crítica, pois é ela, a crítica, que permite um exame cuidadoso das premissas de determinada leitura de mundo, de seus argumentos de sustentação, bem como, de suas consequências, não pode haver também, opinião blindada a crítica (sem a perspectiva da crítica como necessidade de "oxigenação", aqueles que não concordam com o que alguém pensa, são considerados "idiotas", "menores", potencializando uma linguagem fundada na noção do "nós x eles"). Sem a crítica como postura frente ao mundo, o normal e burocrático se derivam em opressão, que pode ser levado a consequências muito graves (o mal, muito presente nas redes sociais, se coloca como perigo no cotidiano concreto do mundo, para muito além da World Wide Web). Um perigo que vem crescendo na contemporaneidade, tendo em vista várias questões, entre elas, o ressurgimento de velhas e novas ideologias que se assentam no ódio e na discriminação - neste cenário, se a dissimulação está presente em muitos discursos, é possível afirmar que discursos agressivos ficaram muito mais evidentes em nossos dias, por vezes, sem o menor constrangimento ${ }^{9}$.

Neste aspecto, Arendt acertou com radicalidade na questão da banalidade do mal. Um cidadão comum, que cumpre com afinco suas tarefas, que tem uma boa relação com seus pares, que, por vezes, se considera bom pai ou boa mãe, ou ainda, bom aluno, que se distancia da realidade e se isola em uma bolha constituída por sua opinião exclusiva de mundo (e por quem compactua com isso), não se trata, absolutamente, de um cidadão inofensivo (especialmente se dotado de poder e/ou armas). Na esteira do pensamento arendtiano, concordando com Muñoz Molina (2015), o mal pode ser causado por pessoas superficiais e medíocres, em nome de razões estúpidas, de ideias de quinta categoria, ou, simplesmente, por uma questão de obediência acéfala, inércia, moda, e/ou ainda, por pressão de comentários alheios.

Que o mal possa ser produzido de forma premeditada, arquitetada e sistematizada, com o intuito de destruir pessoas, a natureza, relações humanas, carreiras etc., já se reconhece a tempos. Mas talvez, outras manifestações menos perceptíveis tenham de ser melhor percebidas

\footnotetext{
${ }^{9}$ Se discursos de ódio são formas de opressão, quando declarados por expresso, mesmo em meio a diversas dificuldades, permitem mapear as fontes geradoras da manifestação, bem como, construir mecanismos de enfrentamento. Mas, quando se escondem por detrás de "boas intenções", 0 enfrentamento se torna ainda mais difícil, tendo em vista, a necessidade de dois movimentos, identificar a mensagem nas suas entrelinhas (haja hermenêutica) e perspectivar posições frente a veladas agressões.
} 
e cuidadosamente examinadas: o mal como resultado de colossal ausência do pensamento e de reflexão, não por acaso, um fenômeno que habita uma sociedade cada vez mais avessa ao pensamento e ao estudo com profundidade. No caso de Eichmann, a ideologia tomou decisões em seu lugar (algo próximo de ações do Governo Federal realizadas ao longo da pandemia), tendo em vista sua diluição no sistema nazista e sua incapacidade de estranhamento reafirmando a máxima, "quando não pensamos, somos pensados".

Por outro lado, temos de reconhecer que o limite do tolerável vem se alterando com 0 passar do tempo, não sem disputas e contradições. Por exemplo, a escravidão, o bullying, o racismo ou a xenofobia são práticas e atitudes que vem sendo cada vez menos toleradas, inclusive do ponto de vista legal. Porém, não podemos desconsiderar que ainda existe trabalho escravo; a humilhação presente no Bullying ainda é bastante perceptível na escola, tanto entre seus muros como nas redes sociais; ainda escutamos ofensas racistas na rua ou em estádios de futebol; ou ainda, são perceptíveis discursos oficiais de alguns países que vêm potencializando, de forma mais ou menos dissimulada, o nacionalismo e a xenofobia - em tempos de isolamento social, a internet tem sido um meio de vazão de discursos desvinculados de qualquer preocupação para além do egoísmo opinativo e sectário de sujeitos que pretensiosamente se agigantam em um sofá, por detrás de um dispositivo digital (celular, por exemplo).

Se por um lado avançamos muito, alcançando uma leitura de mundo mais qualificada em muitos aspectos, por outro, parece que há setores da sociedade dispostos a assumir a barbárie como algo normal, fruto do "mundo como ele é". Algo desta ordem, produz impactos importantes nas relações sociais em nosso tempo, via de regra, resultando em mais agressividade e violência. E isso se manifesta na banalização das palavras, na simplificação do pensamento, na normalização de atitudes que negam o outro, em um cenário no qual, mesmo manifestações oficiais sinalizam para uma simplificação da realidade (um dos pilares de discursos de ódio) e uma violência simbólica que passa a fazer parte do imaginário social como a simples manifestação de uma opinião, fundada em uma pretensa liberdade de expressão, assumindo a ideia (por vezes bem aceita) da força como genuína forma de relacionamento social. Pelo visto, a banalidade do mal representa um grande mal de nosso século, para o qual não temos uma vacina, especialmente, quando o exemplo vem "de cima". Mas, e a universidade com isso?

Neste primeiro tópico, procurei demonstrar, a partir do diálogo com alguns argumentos produzidos por Hannah Arendt, como a "ausência de pensamento" representa um problema na produção e veiculação do mal, a ponto de torná-lo banal, um desafio nada fácil para ser 
enfrentado em nosso tempo. A seguir, apresento argumentos na direção de fundamentar melhor as responsabilidades da universidade frente a estas questões. Parto do princípio de que não somos bons "por natureza", bem como, que a civilidade e a democracia precisam ser sempre reafirmadas pelo diálogo e por nossa condição e disposição política de viver em um mundo comum. Para tal, a educação é a maneira de nos humanizarmos, de nos tornarmos melhor, e a universidade não pode se furtar a esta responsabilidade.

\title{
$2^{\circ}$. MOMENTO - A UNIVERSIDADE COMO LUGAR DE PENSAMENTO
}

\begin{abstract}
Eu digo, senhores, que as reduções propostas para 0 orçamento especial das ciências, letras e artes são negativas por dois motivos. São insignificantes do ponto de vista financeiro e danosos sob todos os outros pontos de vista. [...] E qual é o momento escolhido? E aqui está, me parece, o grave erro político do qual assinalava no início. Qual é o momento escolhido para colocar em dúvida, de uma só vez, todas as instituições? 0 momento em que elas são mais necessárias do que nunca, o momento no qual, ao invés de limitá-las, seria preciso ampliá-las e fazê-las crescer. [...] qual é o perigo da situação atual? A ignorância. A ignorância, muito mais do que a miséria. [...]. É num momento semelhante, diante de um perigo como esse, em que se pensa em atacar, em mutilar, em espoliar todas essas instituições, que tem como escopo, perseguir, combater e destruir a ignorância!

Discurso de Victor Hugo na Assembleia Constituinte de Paris, em 10 de novembro de 1848 (ORDINE, 2016, p. 119-121, tradução minha).
\end{abstract}

Sair do cotidiano da vida exige uma atitude de estranhamento perante o mundo, atitude fenomenológica que permite "dar um passo atrás" (REZER, 2014, 2018). Do contrário, "o mundo nos atropela", tal como se refere o dito popular, a ponto de não conseguirmos mais estranhá-lo. Uma atitude como a do pensamento, sem garantias metafísicas, permite que possamos olhar para nossa condição e para nosso próprio modo de viver (nas trilhas de Hannah Arendt, refletir acerca de "o que estamos fazendo? "), considerando com mais atenção o "clima cultural" no qual vivemos, o que pode nos permitir acessar outras e mais qualificadas perspectivas de mundo.

Em uma conjuntura que vem produzindo um cultivo da ignorância, bem como, uma aversão ao conhecimento, o anti-intelectualismo parece se estabelecer como nova postura frente ao mundo (bem aceita por distintos segmentos, diga-se de passagem). Ao que parece, antes adormecida, a aversão ao conhecimento vem produzindo consequências perniciosas às instituições que o promovem, cada vez mais evidentes na medida em que observamos ataques e cortes nos orçamentos das universidades públicas, com impactos decisivos para a graduação e pós-graduação. Um discurso que pretende colocar a universidade em uma condição subalterna, como se fosse um peso desnecessário para a sociedade contemporânea. 
Felizmente, em meio a pandemia, um movimento na contramão disso vem sendo evidenciado. A universidade, a partir de seu potencial para a produção da ciência, vem sendo chamada a produzir respostas a pandemia, em um movimento no qual a Grande Área de Ciências da Saúde fica em evidência (e há de se reconhecer o esforço daqueles que estão a frente do serviço ou na retaguarda das pesquisas). Porém, não só ela está sendo implicada, pois uma crise como esta exige reações de todos os campos do conhecimento - da sociologia, da economia, da geografia, da educação física, entre tantos outros ${ }^{10}$.

Por outro lado, a produção de discursos desacreditando a ciência (discursos anti-ciência, anti-vacina, entre outros), especialmente nos últimos dois anos, se desdobrou em um atraso significativo no trabalho de prevenção frente a pandemia da Covid-19 que vivemos em 2020 e 2021, tanto em nível nacional como internacional. Da mesma forma, produziram impactos expressivos na "política nacional" de vacinação no contexto brasileiro neste início de 2021 (se a disposição para buscar vacinas fosse próxima da disposição do Governo Federal em sediar a Copa América de 2021, certamente teríamos uma cobertura vacinal bem mais ampla do que temos no memento).

No momento, estamos percebendo que os contextos que se prepararam mais cedo e com mais cuidado para evitar a expansão do contágio (por exemplo, enfatizando a necessidade de isolamento social) conseguiram conter 0 avanço da pandemia de forma mais significativa (caso de países como a Bélgica, Portugal e Alemanha), bem como, tiveram melhores condições de lidar com a segunda onda de contágio do Sarscov-2 (neste momento, a realidade brasileira convive com o prenúncio de uma terceira onda).

Por outro lado, Países como a Inglaterra vem promovendo o retorno gradativo à circulação controlada de pessoas nas vias públicas e estabelecimentos comerciais. Enquanto isso, na realidade brasileira, parece que algumas autoridades públicas estão mais interessadas em insistir em questões como "armar" a população, influenciar no trabalho do Ministério da Saúde, agredir desafetos, atentar contra a democracia, entre outros impropérios, do que produzir uma política sanitária de preservação da vida em meio a crescente onda de contágios na realidade brasileira (desafio que ficou destinado aos prefeitos e governadores enfrentarem, com pequena contribuição do Governo federal, especialmente do Presidente da República e seus seguidores).

10 Por exemplo, não deixa de ser curioso que, em meio ao isolamento social, a música, a arte e a educação física, disciplinas escolares e campos considerados menores, são formas muito boas de enfrentar os dias difíceis de quarentena. Isso nos permite evidenciar a necessidade de reconhecer a importância da universidade como espaço e tempo de formação, considerando a multiplicidade de desafios do mundo contemporâneo, pensando a vida para além do trabalho e da produtividade. 
Considerando este cenário, onde as prioridades governamentais vão se evidenciando de forma muito clara, o teor da carta de Victor Hugo (1802-1885), expresso na epígrafe deste tópico, parece ter sido escrito em 2021 e não, em 1848. Em tempos de elogio e cultivo da ignorância e do obscurantismo, as escolas e universidades são os primeiros "lugares" a serem atacados por discursos oficiais (no caso em tela, não foi a igreja nem as forças armadas, muito pelo contrário). Neste "clima cultural", se torna perceptível um convite a não pensar, bem como, atirar primeiro e perguntar depois ${ }^{11}$.

Nesta onda de anti-intelectualíssimo (algo que pode ser tratado como epistemofobia ${ }^{12}$ ) e elogio a barbárie, a mensagem oficial é de que não é necessário dedicar-se ao pensar, pois temos de ser práticos e objetivos - um "clima cultural" que vem impactando ainda mais a escola e a universidade. Inclusive, em alguns contextos, parece que já não há muita paciência com discursos e manifestações mais alongadas, nem mesmo, a produção de longas cadeias de raciocínio, pois "não podemos perder tempo". No tempo do Fast-food, não é de se estranhar que o Fast-think se torne constituinte do imaginário social13.

Não por acaso, em meio a isso, percebemos um reforço oficial no deslocamento da universidade como instituição republicana para a ideia de universidade como empresa privada. 0 empresariamento é uma realidade que não pode ser desconsiderada por nenhum segmento universitário (certamente, pauta distante de instituições privadas mais interessadas em aproveitar este filão). E aqui, me refiro ao empresariamento como a colonização da universidade

${ }^{11}$ Cabe lembrar a quantidade de vídeos veiculados pelo WhatsApp, ao longo do governo Jair Messias Bolsonaro, contendo discursos recheados de ódio e ressentimento - inclusive, após as eleições em 2018, foram veiculados vários vídeos produzidos por moradores de cidades de vários estados, de armas na mão, sinalizando que, de agora em diante, "as coisas vão ser diferentes". Nessa esteira, o Governo Federal, por meio de decretos, vem ampliando a possibilidade de compra e uso de armamentos e munições, algo que, em um clima cultural tenso, se constitui como uma bomba-relógio, com risco de explodir em mais ou menos tempo.

12 Se não é muito comum vincular horror e medo a conhecimento, especialmente, em meio a "sociedade do conhecimento", a ideia de horror ao conhecimento, mesmo não muito difundida, já foi veiculada de diferentes formas, em diferentes momentos históricos, inclusive recentemente. Já na alvorada da modernidade, Giordano Bruno (1548-1600), teólogo, filósofo, escritor e frade italiano, afirmava que a ignorância é a mãe da felicidade. Num de seus poemas, Fernando Pessoa (1888-1935), poeta português que se aproximou da filosofia como possibilidade para entender sua condição humana, falava sobre 0 "Horror de conhecer" - expressão que virou título de um de seus poemas. Mais recentemente, de forma mais singela, Rui Martinho, professor da Universidade Federal do Ceará, publicou um pequeno texto intitulado "Tempo de epistemofobia", chamando atenção para este fenômeno contemporâneo. Ainda, a Wikipédia apresenta uma lista de fobias, na qual epistemofobia é apresentada literalmente como medo do conhecimento.

${ }^{13}$ Ao que parece, redes sociais como Twitter e WhatsApp vão conformando o pensamento aos seus moldes. Afinal, não são convidativas a veicular textos mais longos, nem mesmo, discussões mais profundas que não cabem em sua formatação. Um risco é que as novas gerações (mas não só elas) passem a deformar seu modo de pensar de acordo com 0 que cabe nestas redes, formatando 0 pensamento de acordo com o uso - via de regra, simplificado, superficial e utilitário.

Revista de Ciências Humanas, Frederico Westphalen - RS, , v. 22, n.1, p. 101-123, jan./abr. 2021. Recebido em: 23/02/2021 $\quad$ Aceito em: 02/06/2021 
pela lógica da universidade privada, tomada como empreendimento comercial, algo extremamente danoso e, cada vez mais presente (inclusive, nas universidades comunitárias, públicas por princípio).

Lembrando as considerações do professor do Departamento de Filosofia da Universidade de Kassel (ALE), Dirk Stederoth, "Quanto mais a universidade se aproxima estruturalmente de uma empresa econômica, tanto mais seus membros assumirão, de forma progressiva, a consciência empresarial, supondo-se que não reflitam permanentemente essas estruturas" (STEDEROTH, 2013, p. 185). Um problema maior ainda é que esta lógica se implementa, geralmente, de modo oculto, sem muito alarde e, quando se percebe, já se enraizou em determinado contexto, tal como uma metástase. Como efeito colateral, no avanço da caracterização da universidade como empresa, percebemos de maneira muito clara, a diminuição do espaço/tempo individual e coletivo para o pensamento e para a reflexão, algo bem de acordo com o movimento anti-intelectual de nosso tempo. Nessa lógica, a universidade ainda poderia contribuir para pensarmos com radicalidade sobre "o que estamos fazendo"?

A crise da universidade na contemporaneidade, pari passu com sua crise econômica, se edifica a partir de uma crise de cultura, gestada no seio dos mais distintos segmentos sociais, algo que que vem gerando uma crise do conhecimento, com desdobramentos significativos para a formação universitária. Ao que parece, de modo geral, na "sociedade do conhecimento", paradoxalmente, vamos perdendo a paciência com o cultivo do conhecimento que não seja útil e aplicável (de preferência, de imediato) ${ }^{14}$. Ao invés de uma formação rigorosa, na qual possamos aprender no presente, a complexa tradição do mundo (o passado) como solo fecundo para a edificação do futuro, olhamos para frente (onde é a frente?), esquecemos do passado e seguimos, mesmo sem saber muito bem para onde.

Em um "clima cultural" desta ordem, não é de se estranhar que artigos e livros (especialmente os clássicos), tenham impacto menor do que, por exemplo, canais de YouTube. Por vezes, youtubers (nova palavra do mundo digital) sem respeito pela verdade, pelo rigor $\mathrm{e}$ pela coerência, em alguns casos podem chegar a uma audiência comparável à de grandes meios de comunicação. Isso merece atenção e cuidado, pois, a formação de opiniões sólidas, sem o devido lastro, as aproxima perigosamente do fundamentalismo (como exemplo, a onda de argumentos sobre o terraplanismo, muito presente em vídeos no YouTube, evidencia um

${ }_{14}$ Possivelmente, a famosa frase de Aristóteles, expressa em sua Metafísica, afirmando que os homens têm por princípio, o desejo de conhecer, teria de ser adjetivada em nosso tempo. Sim, o desejo de conhecer, mas, aquilo que é útil, aplicável e produza lucro (de preferência, de imediato). 
desprezo e um ceticismo frente a questão do conhecimento edificado ao longo da história da humanidade).

Desta forma, é quase evidente (embora ainda se coloque sob uma camada de dissimulação) a efervescência de um culto à ignorância, onde mais importante que a busca pela verdade, é estar certo. Se Descartes (1596-1650) afirmou no Século XVI, "Penso logo existo", percebemos, no Século XXI, o crescimento de outra máxima, "Acredito, logo, existe", o que vem gerando uma violência simbólica destrutiva para as relações sociais através de discursos baseados na crença e na convicção da fé (a "verdade" que prescinde de provas). Assim, não é de se estranhar, embora devamos combater, a proliferação de mensagens agressivas, de ódio, infundadas ou remontadas, na direção de dar conta da pretensão do egocentrismo opinativo da crença que se move pela negação do outro e se coloca como ingrediente perverso para a produção e veiculação de discursos do ódio.

Para lidar com isso, há necessidade de potencializar uma formação ética (na família, na escola e na universidade), embora imersos em um "clima cultural" adverso a isso. Já no Século XIX, Victor Hugo procurava demonstrar a necessidade de uma formação cultural ampla, rigorosa, para lidar radicalmente com o mal da ignorância. Atualmente, passados quase dois séculos, parece que pouco aprendemos, pois, seu discurso continua forte e necessário de ser lembrado15.

Se é possível argumentar que a banalização do mal tem como um de seus motores a leitura simplificada de mundo, bem como, a incapacidade para o pensamento e a reflexão, a universidade deve se colocar como uma instituição que necessita potencializar o avesso disso. Um esforço que exige uma postura mais rigorosa, ponderada, profunda e qualificada tanto nos

15 Corroborando com a pergunta do psicanalista Mario Corso (CORSO, 2019), por que será que não produzimos mais gênios, como, por exemplo, Leonardo da Vinci, mesmo com tanto acesso à informação? Talvez, porque, quando muito, treinamos sujeitos unidimensionais, monotemáticos, fadados apenas a uma via do saber, como se fosse o melhor destino de sua aptidão, privando-o de unir os pontos desconexos da realidade. Um pensador monotemático não experimentará a humildade de se defrontar com as dificuldades inerentes a campos que ele não domina (geralmente, ouvimos a expressão: esta não é a minha área). Nesse caso, suas maiores capacidades, ao invés de florescerem em uma personalidade complexa, pela hipertrofia, acabam estreitando seus horizontes. Certamente, não podemos a tudo tratar. Mas ao mergulhar nas reentrâncias do conhecimento, acabamos percebendo que, muito menos do que por vezes imaginamos, há nexos entre campos do conhecimento que, aparentemente, estão muito distantes. Por exemplo, se as conexões entre Educação Física e Medicina são perceptíveis, há de se reconhecer também, formidáveis possibilidades de aproximação da Educação Física com a Filosofia ou Sociologia. Porém, estas conexões não nos são "naturalmente" dadas, mas sim, necessitam ser produzidas teoreticamente. Gênios como Leonardo da Vinci não se contentavam com fronteiras, borrando-as de acordo com sua inserção em diferentes dimensões humanas, como arte e ciência. 
processos de formação, como no exercício da crítica ao excesso de manifestações de ódio veiculadas em nome da liberdade de expressão.

Aprender a ouvir mais e a pensar antes de falar, o que implica em estudar mais e se posicionar de forma menos apressada, bem como, "perguntar antes de atirar", poderiam ser posturas fomentadas nos ambientes universitários, tendo por prerrogativa, a reflexão, o estudo e o diálogo, em tese, motores da atividade intelectual que fundam esta instituição. Inclusive, a universidade tem o compromisso de ensinar que não podemos nos embriagar com uma pseudoliberdade irrestrita, uma ilusão que vem com a modernidade e a auto instituição do sujeito que pensa, portanto, existe, tal como se fossemos sujeitos autônomos no mundo. Uma perspectiva dessas desconsidera que a vida em sociedade não se faz, nem por meio do solipsismo, muito menos por meio de guetos independentes entre si, mas sim, com os outros, assumindo, portanto, que os outros possuem influências significativas em nossa forma de ser, pensar e agir e, portanto, devem ser considerados, mesmo quando criticam posições e leituras de mundo das quais compartilhamos.

A ilusão da autonomia ou da liberdade plena, irrestrita, se configura contraditoriamente como sua própria negação. Talvez, esta seja uma das maiores contradições de nosso século: 0 uso pretensamente radical de nossa liberdade de expressão representa uma ditadura da força que nega nossa própria possibilidade de sermos livres (se o totalitarismo, lembrando Hannah Arendt, é a negação mais radical da liberdade, a liberdade irrestrita representa também, sua própria negação). Isso requer o reconhecimento de que ser livre não se trata de uma característica "natural" do humano, mas sim, uma conquista histórica produzida no mundo entre seres humanos, fruto da tensão entre determinações internas e externas, entre a autonomia, sempre relativa, e a heteronomia que nos impacta.

Portanto, não há possibilidade de sermos radicalmente autônomos ou livres, pois isso significa a negação do outro em nome de minhas próprias determinações. Nossa liberdade é sempre relativa a um sistema complexo de valores e normas, produzido culturalmente ao longo da história da humanidade, em meio a um jogo de forças, derivado da disputa de distintos projetos societários que se movimentam em escala global.

Neste "clima cultural", percebemos a crescente veiculação de mensagens de ódio pelas redes sociais, bem como, para além delas ${ }^{16}$. 0 crescimento de discursos de ódio, aliado a ideia

16 Várias mídias veicularam, no final de 2019, uma "brincadeira" de alguns estudantes portugueses da Faculdade de Direito da Universidade de Lisboa. Um cartaz xenófobo, colado sobre uma caixa com pedras, produzido por um grupo de estudantes portugueses, oferecia pedras grátis para atirar em alunos do Brasil. "Grátis se for para atirar a um zuca" (uma gíria para se referir a brasileiros). Os alunos 
de que as relações humanas e temas complexos podem ser "discutidos" por meio de poucas palavras expressas de forma precária, muitas vezes, sem a devida ponderação, vem potencializando a pobreza intelectual e o esfacelamento do diálogo como modo de produção da vida coletiva. Em alguns casos, parece que o mundo vai acabar se alguém não manifestar sua opinião sobre determinado assunto, potencializando a veiculação de mensagens por impulso, sem o devido tempo do pensamento ${ }^{17}$.

Nesta esteira, cresce a banalização da ideia de que podemos pensar da forma como quisermos, sem pensar nas consequências de nossas escolhas, desconsiderando arquétipos que formam um inconsciente coletivo, bem como, a produção de formas coletivas de pensamento que, sem dúvida, impactam nossa forma de ver o mundo. Assim, a diferença de pensamento, tão saudável para qualquer democracia, pode se instituir como uma ditadura da opinião, fenômeno que polariza discussões, impede o diálogo e simplifica a complexidade do mundo. Ou seja, quando nos deparamos com alguém que possui "opinião formada" sobre temas polêmicos e complexos, nos deparamos com alguém que parou de pensar sobre algo e já está, sem maiores problematizações, na verdade. Portanto, não necessita mais dialogar a respeito de algo, apenas, professar a "boa nova" aos demais.

Certa feita, ouvi de um aluno de graduação: "Mas eu penso diferente e tenho o direito de ter a minha opinião". Em última instância, a afirmação está correta. Porém, cabe avisar aos desavisados, que ter direito de pensar diferente não nos desobriga a examinar os argumentos de justificação que sustentam nossas decisões no campo da moral, da política, da educação, da economia e, inclusive, nos temas do cotidiano. Ou seja, a possibilidade de pensar diferente não exclui nossa responsabilidade (ser responsável é responder por nossas formas de ser, pensar e agir) de examinar as bases argumentativas que sustentam nosso discurso e, principalmente,

identificados afirmaram se tratar apenas de uma "brincadeira". Bem, xenofobia não é brincadeira, nem os desdobramentos que ela pode produzir, um tema que merece cuidado, especialmente em uma universidade.

${ }^{17}$ Sobre isso, sugiro outro texto de Mario Corso (2018), "Gênios que driblam o egoísmo para nos ensinar". 0 texto, redigido com fina ironia, afirma que "Seguramente, uma das razões porque nosso mundo nunca esteve tão bem, é porque nunca antes, uma tão grande, globalizada e cosmopolita comunidade de iluminados, emitiu tantas opiniões sobre tudo com tal presteza". Da mesma forma, pergunta se nos damos "[...] conta da lentidão dos jornalistas, presos ao antigo modelo das fontes idôneas, pesquisas e checagem de fatos? Os samaritanos das redes sociais são livres disso, permitindo a rápida circulação de suas impressões sobre todas as esferas da existência". Finaliza afirmando que, "Parando a brincadeira, a ironia, faz tempo que sofro com o vale-tudo cultural das redes sociais. Perdoem meu mau-humor, mas finalmente as pessoas estão se dando conta que jornalismo sem jornalistas, ciência sem cientistas, filosofia sem filósofos, só poderia dar em nada. As redes são ótimas para conectar pessoas, ponto. Para o resto, elas têm a profundidade das fofocas". 
suas consequências posteriores ${ }^{18}$. Portanto, pensar diferente não nos desobriga de perspectivar possíveis desdobramentos de nossa forma de pensar na concretude do mundo (pensar é intervir no mundo). Do contrário, nos resta a prisão da convicção nos caminhos do fundamentalismo, um perigo eminente em muitos contextos, inclusive na universidade.

Lidar com isso, especialmente na universidade, exige o esforço do estudo, da reflexão e do pensamento. Nossa relativa liberdade de expressão (não é possível alcançar a maioridade sem dor) nos obriga a uma análise radical de nossa perspectiva de mundo - por vezes, expressa, em meia dúzia de palavras escritas no WhatsApp ou no Twitter.

Neste "clima", percebemos o surgimento do que vem sendo denominado de pósverdade ${ }^{19}$. E na cruzada por estar certo, aqueles e aquelas que não concordarem passam a ser "eles", os inimigos. Reconhecer que a verdade é sempre uma construção histórica, produzida sob determinadas circunstâncias, não nos autoriza a produzir, irresponsavelmente, efeitos de verdade como se fossem meras News, sem considerar os impactos disso, por menor que seja seu alcance. A banalização desta postura irresponsável, sem dúvidas, se coloca como solo fértil para a polarização, fenômeno que leva muitas vezes, a uma confusão que se constitui como solo fecundo para convictos discursos de ódio (nas redes sociais, mas também, para muito além delas).

Não basta pronunciar em larga escala uma pseudo-verdade, simplesmente por exemplo, por entendermos que questões de gênero são de esquerda e não devem constar na agenda de uma sociedade civilizada e de bons costumes como a nossa. Ou que não houve tortura ao longo do golpe midiático-civil-militar após 1964. Ou ainda, que a terra é plana (?!). Qualquer reinterpretação, revisionimo ou negacionismo da história necessita de elementos mais concretos do que nosso desejo de que seja verdade, bem como, amplo debate público, para muito além da simplificação presente em alguns canais do YouTube.

\footnotetext{
${ }^{18}$ Cabe destacar que a tolerância ilimitada representa a morte da tolerância. Para que a tolerância seja uma potência para o bem viver, ela necessita do cultivo da intolerância. Ou seja, não podemos a tudo permitir, pois tolerar implica em responsabilizar-se por algo (DICKEL, 2006). Por exemplo, temos de ser intolerantes frente a tudo que fragiliza a vida em sociedade e nega o outro em sua possibilidade de bem viver.

19 Terraplanismo, revisionismo ou negacionismo (do Golpe midiático-civil-militar de 1964), entre outras narrativas edificadas com base na desconstrução irresponsável, bem como, na crença e no desejo de poder, se manifestam com a pretensão de "redefinir" a história, com vistas a construir uma base de sustentação para projetos político-culturais (no caso em tela, de ordem liberal e conservadora). Nessa esteira, percebemos o crescimento da pós-verdade, expressão bastante utilizada nos últimos anos, que corresponde a narrativas em que fatos objetivos têm menos importância do que paixões, interesses, crenças pessoais e o desejo de estar certo. Se fatos são construções históricas, toda narrativa deve se assentar em critérios de justificação dotados de sentido no mundo comum. Sem isso, não passam de embustes.
} 
Desta forma, o cultivo da ignorância, da confusão e da ideologização da história (pecados históricos tanto da esquerda como da direita política e intelectual), favorecem o uso da força como forma genuína de relacionamento social, banalizando a produção do mal como algo aceitável ou mesmo necessário. A radicalidade do egocentrismo opinativo, que se coloca no mundo comum sem critérios de justificação dotados de sentido, leva, invariavelmente, ao fundamentalismo, um câncer impregnado nas diversas sociedades que constituem o mundo contemporâneo (certamente, algumas delas evidenciam isso de forma mais explícita, outras, de forma mais velada).

Portanto, a função social da universidade se coloca na direção de tensionar a realidade como problema, e não, assumir a condição de uma clínica de adaptação para o mundo (atender demandas), no qual os egressos irão exercer uma profissão ${ }^{20}$, esterilizados de sua capacidade de crítica, discernimento e resistência (afinal, como se refere o dito popular, "o mundo é assim mesmo"). Ser universidade é reconhecer a complexidade do mundo, de suas sociedades e de sua diversidade como possibilidade, como problema e como projeto, em um movimento que não pode contribuir com o corrente processo de simplificação de mundo, base sistêmica para a produção da barbárie, na forma de discursos de ódio, quer seja em redes sociais, quer seja no cotidiano do mundo da vida (Lebenswelt).

O fraquejo do conhecimento como necessidade do humano dos seres, bem como, das tarefas de estudar e produzir críticas com profundidade, pode representar o suicídio da universidade como instituição republicana que tem, no conhecimento, seu princípio fundante, seu pressuposto de existência. $E$ isso vai se agravando na medida em que a impaciência com 0 cultivo do conhecimento, o elogio da ignorância e um utilitarismo imediatista vai deslocando as finalidades da universidade para a formação profissionalizante de estudantes adaptados a uma globalização neoliberal altamente excludente ${ }^{21}$.

\footnotetext{
${ }^{20}$ Algo que, pelo movimento que vemos crescer, se torna cada vez mais difícil e raro, considerando as cada vez maiores taxas de desemprego. Nas vias de um discurso hegemônico, muitos estudantes já vão sendo ensinados a ver na informalidade ou no "empreendedorismo", as saídas possíveis. Isso implica em aprender a abrir mão de direitos fundamentais do trabalhador, assimilando a "nova realidade" do mundo do trabalho, precarizado, individualizado e com cada vez menos direitos. Basta ver o drama dos "empreendedores" em tempos de pandemia, socorridos, não pela mão invisível do mercado (expressão de Adam Smith), mas sim, pela mão visível do Estado. Imaginemos a crise sanitária que vivemos sem a presença do Estado?

${ }^{21}$ A globalização neoliberal corresponde a um novo regime de acumulação do capital, um regime mais intensamente globalizado que os anteriores, que visa, por um lado, dessocializar o capital, libertando-o dos vínculos sociais e políticos que no passado garantiram alguma distribuição social e, por outro lado, submeter a sociedade no seu todo à "lei do valor", no pressuposto de que toda atividade social é mais bem organizada quando organizada sob a forma de mercado. A consequência principal desta dupla transformação é a distribuição extremamente desigual dos custos e das oportunidades produzidos pela
} 
Ao assumir com radicalidade que se constitui como Lugar do Pensamento, a universidade se colocaria como instituição republicana que tem por prerrogativa combater, por meio da força do argumento, e não do argumento da força, a banalidade do mal presente no cotidiano da sociedade contemporânea. Discursos de ódio são produzidos e veiculados a partir do ressentimento (aqui, uma chave de leitura que necessita ser melhor examinada) de quem nunca teve vez ou voz; mas também por pessoas comuns, considerados inclusive, "cidadãos de bem"; bem como, por aqueles que governam, por vezes, que assumem o poder sem o devido saber22.

Uma tarefa precípua da educação, por conseguinte, da universidade, é romper com 0 imediato e com aquilo que parece "natural" no âmbito das práticas e das relações humanas. Nessa direção, a universidade necessita assumir com radicalidade o combate a discursos de ódio que circulam no mundo comum, inclusive, alguns produzidos e veiculados por ela própria (por meio daqueles que a fazem ser no cotidiano). O que torna essa discussão ainda mais complexa, é saber se a universidade contemporânea, por meio daqueles e daquelas que a constituem, articulados a ampla esfera pública, terão disposição e condições objetivas para enfrentar este grande desafio, diga-se de passagem, um desafio bem de acordo com o que se espera de uma instituição republicana como a universidade, que tem no conhecimento seu princípio fundante.

\section{CONSIDERAÇÕES FINAIS}

Se os argumentos com os quais opero ao longo do texto estiverem corretos, a universidade brasileira, em seus mais diversos segmentos, necessita realizar uma autocrítica radical (bem verdade, algo cada vez mais distante das universidades privadas e nem sempre presentes no âmbito das públicas). Isso não se realiza, nem com corporativismos, nem com políticas educacionais como as que se desenham no atual Governo Federal - como por exemplo, a ideia de "cortes" no orçamento das universidades associada a ideia de economizar "despesas" que não são percebidas como "investimento".

globalização neoliberal no interior do sistema mundial, residindo aí a razão do aumento exponencial das desigualdades sociais entre países ricos e países pobres e entre ricos e pobres no interior do mesmo país. (SOUSA SANTOS, 2002).

22 Se algum dia, a velha máxima de Francis Bacon (1561-1626), "saber é poder" já fez sentido, na atualidade, ela se encontra em um perigoso declínio, sendo substituída paulatinamente por uma perigosa noção de poder sem saber, doença que atinge muitas instituições na contemporaneidade, reforçada por discursos oficiais de um Governo Federal mais preocupado em fomentar o ódio do que governar com sabedoria. 
Frente ao grande volume de discursos que se colocam em nosso horizonte cotidiano, há de se ter discernimento (aqui outra chave de leitura no pensamento de Hannah Arendt) para lidar com tantos desencontros e superficialidades, filtros que nos ajudam a decidir o que pensar com maior qualidade - este "polimento" de nossas lentes se dá por meio de nossa formação, inclusive e especialmente, na universidade. Potencializar a universidade como Lugar de pensamento, nos coloca em uma condição de responsáveis pelo mundo, bem como, responsáveis por produzir discursos que potencializem a capacidade humana de pensar de forma qualificada e profunda, talvez um esforço que nos permita, pela radicalidade da atividade intelectual, compreender, com profundidade, problemas complexos que nos acometem na contemporaneidade, tal como a produção e veiculação de discursos de ódio.

$E$, se a produção e veiculação de discursos de ódio são crescentes em nosso tempo, nos cabe examinar esta questão com cuidado e profundidade no âmbito universitário, e não, "embarcar na onda", combatendo fogo com fogo, na lógica do olho por olho, práticas que nos conduzirão a destruição e/ou a cegueira. Se faz necessário compreender como e sob que condições o discurso de ódio se coloca, por vezes, a partir daqueles e daquelas que possuem a convicção de lutar contra discursos desta ordem. Ou seja, em nome do bem, o mal se coloca como realidade no mundo (algo que nos remete a outros eventos históricos, tal como 0 movimento das Cruzadas realizada no complexo mundo medieval, ou o processo de Colonização que acomete nosso país desde o Século XVI).

O mal pode ser produzido e veiculado por autoridades e cidadãos comuns, que não reconhecem estar produzindo barbárie por meio de suas opiniões (por vezes, homofóbicas, xenófobas, sexistas ou racistas), mesmo que ela represente a negação do outro. Em meio a isso, há de se reconhecer que também há casos de total irresponsabilidade com os impactos do que se "diz" em mensagens de negação do outro, fruto de uma maldade humana que não podemos tolerar.

Nessa direção, o "discurso de ódio", como fenômeno atual, deve constituir pauta corrente na agenda da universidade, em espaços de discussão na direção de fomentar 0 pensamento e o respeito a complexidade de temas que não são nada fáceis de lidar. Da mesma forma, levar este debate para a ampla esfera pública representa um desafio nevrálgico para 0 âmbito universitário. Discussões desta ordem devem estar presente, mas também, sair do meio acadêmico e ir para a ampla esfera pública, andar "na boca do povo", como forma de discussão, empoderamento e de reconhecimento de sua complexidade. E isso não se faz pelo WhatsApp 
ou pelo Twiter, mecanismos perfeitos para professar "A" verdade, reforçar certezas e fomentar convicções, algo bem longe de promover o pensamento alargado.

Assim, fica um desafio: ampliar este debate na ampla esfera pública, de modo que questões como o discurso do ódio e a liberdade de expressão possam ser postos como problemas culturais de nosso tempo, dignos de constituírem a agenda de distintos segmentos sociais, do Poder Público e das muitas instituições de ensino superior presentes em diferentes cidades e regiões brasileiras. Questões como "liberdade de expressão" e "discursos de ódio" devem estar em discussão constante, pois a invisibilidade da barbárie representa sua manutenção e incorporação em distintos modos de ser no mundo. Por exemplo, a bem pouco tempo atrás, não havia maiores problemas em fazer piadas com homossexuais ou negros. Derivado de discussões nos mais diversos âmbitos da esfera pública, é perceptível a mudança de comportamento em muitos segmentos da sociedade (mesmo em meio a um aparente retrocesso gerado por um clima cultural capitaneado por setores do Governo Federal). Talvez, neste caso, tenhamos uma amostra muito significativa de como a produção de discursos incide em nossa potência de produzir mundo.

Se é que a barbárie pode ser combatida pela educação (e eu entendo que sim), a universidade (bem como, a escola) tem por responsabilidade precípua, mais que formar para 0 trabalho, ensinar sobre a necessidade de impormos limites a nós mesmos, aos desejos e caprichos que possuímos, a ir contra si, pois o mundo não nos pertence. Sem isso, a vida em sociedade não seria possível, pois viver em sociedade é exercer nossa capacidade de renúncia em nome do mundo comum, mesmo que, muitas vezes, não reconheçamos isso no cotidiano. Não assumir isso é potencializar uma adolescência eterna que não admite a necessidade de frearmos nossos impulsos, assumindo essa condição como forma legítima de ser, algo bem distante da maioridade necessária para lidar com a complexidade de problemas como os que abordo neste texto.

A universidade deve ensinar que existem outros mundos e que outros mundos são possíveis. Não pode compactuar com um imaginário social que, vendo-se fragilizado frente a violência, cultiva o ressentimento e assume o discurso de violência como forma de viver em paz, o que gera um paradoxo incomensurável, que vai criando uma narrativa que naturaliza o ódio, normaliza a agressividade, bem como, desacredita e faz desacreditar que a paz e o bem podem ser o motor das sociedades que existem em âmbito planetário.

Assim, ao assumir a responsabilidade pelo mundo comum, a universidade deve ser um tempo e lugar onde se coloca a questão do ódio e do ressentimento como tema de debate, 
elevando temas que vão sendo naturalizados na torre de marfim do senso comum (como se refere Hannah Arendt) e que merecem tratamento na formação universitária. Fóruns de discussão, seminários, aulas abertas, entre outros, são movimentos que permitem tocar em feridas abertas no corpo social contemporâneo, que sem a atividade do pensamento, tem apenas a barbárie como possibilidade ${ }^{23}$.

A guisa de conclusão, retomando a arquitetura arendtiana, cabe considerar que 0 objetivo de uma educação totalitária (tanto de esquerda como de direita) nunca foi formar cidadãos críticos, pensantes, com discernimento e ponderação para "tocar a vida", tendo o mundo comum como referência. Muito pelo contrário, uma educação totalitária objetiva destruir a capacidade humana de pensar e refletir criticamente sobre o mundo. Uma responsabilidade da universidade deveria ser denunciar isso radicalmente e propor uma formação cultural ampliada e ética, bem como, qualificada no amplo campo das diversas ciências, por meio do exemplo, da palavra e do afeto. Sem a atividade do pensamento, mas também da sensibilidade e do exemplo, isso se constitui como uma impossibilidade. Aliás, especialmente na universidade, mas também, para além dela, abdicar de pensar deveria ser reconhecido como um crime contra a humanidade, pois a "ausência de pensamento" representa solo fecundo para a banalidade do mal, porta de entrada para fundamentalismos dos mais diversos. Que não esqueçamos de Eichmann, das análises de Hannah Arendt, muito menos, da carta de Victor Hugo...

\section{REFERÊNCIAS}

ARENDT, Hannah. A crise na educação. In: Entre o passado e o futuro. 3. ed. São Paulo: Perspectiva, 1992.

ARENDT, Hannah. Homens em tempos sombrios. São Paulo: Companhia das Letras, 1999.

ARENDT, Hannah. Eichmann em Jerusalém: um relato sobre a banalidade do mal. São Paulo: Companhia das Letras, 2000.

ARENDT, Hannah. A condição Humana. 10ª Ed. Rio de Janeiro: Forense Universitária, 2008.

ARENDT, Hannah. Origens do totalitarismo. 1. ed. São Paulo: Companhia de Bolso, 2012.

BRASIL. Constituição Federal de 1988. Promulgada em 5 de outubro de 1988. Disponível em: http://www.planalto.gov.br/ccivil_03/constituicao/constituicao.htm, acesso em 05 de janeiro de 2021.

${ }^{23} \mathrm{E}$ aqui reside o paradoxo maior deste texto. Se a "ausência de pensamento" representa uma abertura fecunda para a banalidade do mal, o mal também tem origem nas faculdades racionais que nos fazem (relativamente) livres, derivados de nossa liberdade de pensar. 
CAVALCANTE FILHO, João Trindade. 0 discurso do ódio na jurisprudência alemã, americana e brasileira: como a ideologia política influencia os limites da liberdade de expressão. São Paulo: Saraiva, 2017.

CORSO, Mario. Gênios que driblam o egoísmo para nos ensinar. Jornal Zero Hora. Edição de 05 de maio de 2018. Disponível em: https://gauchazh.clicrbs.com.br/colunistas/mariocorso/noticia/2018/05/genios-que-driblam-o-egoismo-para-nos-ensinar-

cjgsjm22005vq01qodc5zihax.html, acesso em 10 de dezembro de 2020.

CORSO, Mario. Exatas e humanas: por que não se produzem mais gênios? Jornal Zero Hora. Edição de 27 de abril de 2019. Disponível em: https://gauchazh.clicrbs.com.br/colunistas/mariocorso/noticia/2019/04/exatas-e-humanas-por-que-nao-se-produzem-mais-genioscjuygkier01hz01p7fnof55p7.html, acesso em 15 de dezembro de 2020.

DICKEL, Adriana. O que tolerar? O que não tolerar? Ensaio sobre o lugar da tolerância na educação. In: FÁVERO, Altair; DALBOSCO, Claudio A.; MARCON, Telmo. Sobre filosofia e educação: racionalidade e tolerância. Passo Fundo: DAAD-UPF, 2006.

KRAUSE, Peter. Rezension zu: STANGNETH, Bettina: Eichmann vor Jerusalem. Das unbehelligte Leben eines Massenmörders. Hamburg (ALE): 2011. Disponível em: www.hsozkult.de/publicationreview/id/rezbuecher-16265, acesso em 15 de dezembro de 2020. ORDINE, Nuccio. L'utilitá dell'inutile - Manifesto. Firenze (ITA): Bompiani, 2016.

REZER, Ricardo. Educação Física na Educação superior: trabalho docente, epistemologia e hermenêutica. Coleção Sul. ABEU Sul. Chapecó: Argos, 2014.

REZER, Ricardo. Horizontes para pensar a universidade comunitária no contemporâneo: 30 teses... ljuí: Unijuí, 2018.

SILVA, Juremir Machado da. Golpe midiático-civil-militar. 8ª . Ed. Porto Alegre: Sulina, 2017. STEDEROTH, Dirk. A ideia da formação (universitária) e sua deformação econômica: um cântico final. Revista Espaço Pedagógico, v. 20, n. 1, Passo Fundo, p. 175-188, jan./jun, 2013.

SOUSA SANTOS, Boaventura de. Prefácio. In: Sousa Santos, Boaventura. (Org.). Produzir para viver: os caminhos da produção capitalista. Rio de Janeiro: Civilização Brasileira, 2002.

STANGNETH, Bettina. Eichmann vor Jerusalem. Das unbehelligte Leben eines Massenmörders. Hamburg (ALE): 2011.

XARÃO, José Francisco Lopes. Banalização da "Banalidade do Mal". Pensando - Revista de Filosofia Vol. 8, № 15, 2017. Disponível em:

https://ojs.ufpi.br/index.php/pensando/article/view/4548, acesso em 12 de abril de 2020. 